\title{
4-DOF Robot Arm for Pick and Place Process
}

\author{
Myat Noe Wai ${ }^{1}$, Thwe Thwe Htoo ${ }^{2}$, Lu Maw ${ }^{3}$ \\ Faculty of Electronic Engineering \\ University of Technology (Yatanarpon Cyber City) \\ Pyin Oo Lwin, Mandalay \\ Myanmar
}

\begin{abstract}
The more increase in the number of industries in developing countries, the more laborers or workers are required. To reduce the cost of the labor force and to increase the manufacturing capacity of industries, advanced robot arms are more needed. This paper aims to eliminate the control of the robot arm for picking and placing the object. The arm is constructed in this research with four joints, four links, and four Dc motors to drive the robot arm. Arduino Microcontroller is used to generate the required control signals for DC motors. This paper involves the PID-based kinematic control system which is used for doing successful robotic manipulation tasks in its workspace. Standard DH parameter convention is used to calculate forward kinematics. An analytical method for a closed-formed solution of inverse kinematics is applied to solve the unknown joint angles required for the autonomous position of a robot arm. Four DC motors of four joints are controlled using PID techniques for position control. And for the interface control system via PC, a MATLAB GUI is used to interactively communicate with Arduino controller. The control of this pick and place robot arm system is fully tested in real-time, and the results show that the system has a precise control system for obtaining a good system performance.
\end{abstract}

Key Words: 4-DOF Robot, DC motor, Pick and place, MATLAB GUI, PID.

\section{INTRODUCTION}

As manpower becomes more expensive, there is a need to find cheaper, faster, and safer ways of performing tasks that grow exponentially. A robot, according to the Robot Institute of America, is "A reprogrammable multifunctional manipulator designed to move material, parts, tools, or specialized devices through various programmed motions for the performance of a variety of tasks". [1] The robot manipulator is one of the motivating disciplines in industrial and educational applications, and an essential branch to control sciences because of its intelligent aspects, nonlinear characteristics, and real-time implementation. A robotic arm control is a challenging and demanding activity in the industrial field as well as military and other applications. A robotic arm is a robot manipulator, normally programmable with analogous functions to a human arm. [3]

There are four main robot configurations such as (a) A Cartesian robot, (b) A cylindrical robot, (c) Polar robot or Spherical robot, and (d) Joint arm robot or articulated robot. Whatever the kinds of robot manipulator may be provided with, robot performance measures the high quality and large quantity of work that it can do in the desired place. The most important applications of industrial robots are material handling, welding, assembling, dispensing, and processing where the robotic arm manipulator needs to perform pick and place operations incessantly. One such an industrial standard robot is a generic serial arm which consists of a base, a link or series of links connected at joints, and an end effector. [4] These links and joints make up kinematic chains that form the basic structure of the equipment.

The purpose of this paper is to design and construct a four-degree-of-freedom revolute joints robot manipulator, implemented as base, shoulder, elbow, and wrist which would be flexible in motions to move from one position to another with smooth movement. The paper is presented as follows. In Section (1), the introduction of the research is illustrated. Section (2) explains methods using in research and Section (3) shows analytical calculation. After Section (4) system overview of the robot arm, the 
next section is about testing experimental results and observation of the reality stage using the designed small special robot with four revolute joints. Finally, Section (6) presents the conclusion of this paper.

\section{METHOD USING IN RESEARCH}

The kinematics method is the motion geometry of the robot manipulator from the reference position to the desired position with no regard to forces or other factors that influence robot motion. There is two main class in kinematics: Forward kinematics and inverse kinematics. Forward kinematics is used for transferring the joint variable to get the end-effector position. On the other hand, inverse kinematics will be applied to find a joint variable from the end-effector position. The structure of the articulated robot arm design is represented in Figure 2.1.

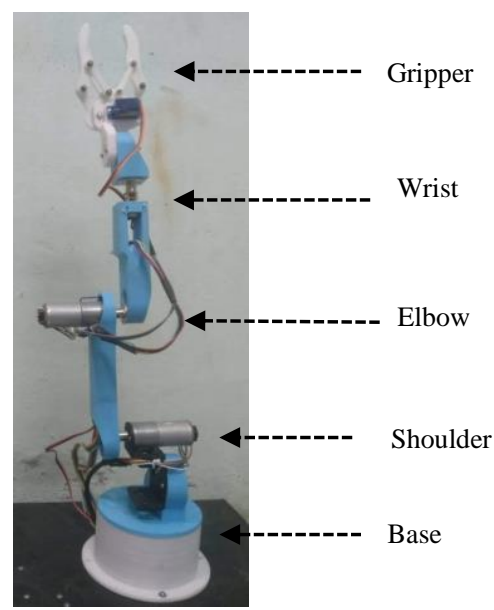

Figure 2.1: Structure of the articulated robot arm design

\section{ANALYTICAL CALCULATION OF RESEARCH}

This study proposes the kinematics method and controls a 4 DOF arm robot manipulator applied in the pick and place process. The proposed method ensures the right design of the mechanical system and the smoothness of the end-effector motion.

\subsection{DH Convention}

Denavit-Hartenberg (DH) convention is commonly used in the kinematics analysis of the robotic manipulator. It is based on attaching a coordinate frame at each joint and specifying four parameters known as DH parameters for each link, and the DH table is constructed utilizing this parameter. [5] These parameters are the twist angle $\alpha_{i}$, link length $a_{i}$, link offset $d_{i}$, and joint angle $\theta_{i}$. The relationship between the joint variables and the position, and also the orientation of the gripper, is driven using the following DH parameters as illustrated in Table 2.1, and the structure of the robot arm design according to the DH parameters is shown in Figure 3.1.

Table 2.1. DH parameter

\begin{tabular}{|c|c|c|c|c|c|c|}
\hline Joint $\mathbf{i}$ & Joint Name & $\boldsymbol{\theta}_{\mathbf{i}}$ & $\begin{array}{c}\mathbf{d}_{\mathbf{i}} \\
(\mathbf{m m})\end{array}$ & $\begin{array}{c}\mathbf{a}_{\mathbf{i}} \\
(\mathbf{m m})\end{array}$ & $\boldsymbol{\alpha}_{\mathbf{i}}$ & $\begin{array}{c}\text { Range } \\
\boldsymbol{\theta}_{\mathbf{i}}\end{array}$ \\
\hline $\mathbf{1}$ & Base & $\theta_{1}$ & 164 & 0 & $-90^{\circ}$ & -120 to +120 \\
\hline $\mathbf{2}$ & Shoulder & $\theta_{2}$ & 0 & 120 & 0 & -30 to \\
& & & & & & -120 \\
\hline $\mathbf{3}$ & Elbow & $\theta_{3}$ & 0 & 0 & $90^{\circ}$ & +30 \\
\hline $\mathbf{4}$ & Wrist & $\theta_{4}$ & 280 & 0 & 0 & -120 to +120 \\
\hline
\end{tabular}




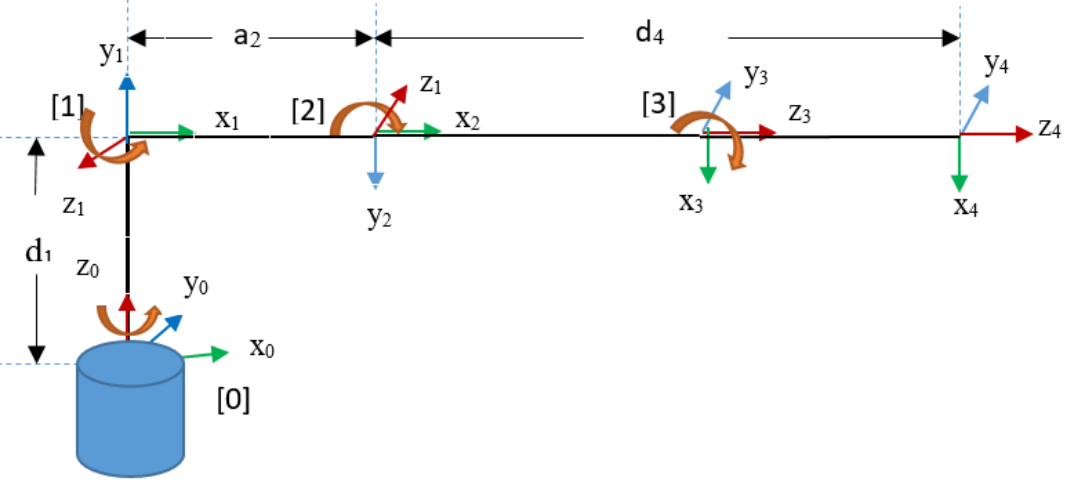

Figure 3.1: Link parameters of an articulated robot

\subsection{Forward Kinematic Model}

The forward kinematic model represents the relations calculating the operational coordinates, giving the location of the endeffector, in terms of the joint coordinates. After developing D-H parameters for each link as shown in Table 2.1, a homogeneous transformation matrix can be easily established considering frame $\{i-1\}$ and frame $\{i\}$ transformation.

$$
\begin{aligned}
{ }^{i-1} T_{i}=\operatorname{Rot} & \left(z, \theta_{i}\right) \cdot \operatorname{Trans}\left(z, d_{i}\right) \cdot \operatorname{Trans}\left(x, a_{i}\right) \cdot \operatorname{Rot}\left(x, \alpha_{i}\right) \\
T_{i} & =\left[\begin{array}{cccc}
\cos \theta_{i} & -\cos \alpha_{i} \sin \theta_{i} & \sin \alpha_{i} \sin \theta_{i} & a_{i} \cos \theta_{i} \\
\sin \theta_{i} & \cos \alpha_{i} \cos \theta_{i} & -\sin \alpha_{i} \cos \theta_{i} & a_{i} \sin \theta_{i} \\
0 & \sin \alpha_{i} & \cos \alpha_{i} & d_{i} \\
0 & 0 & 0 & 1
\end{array}\right]
\end{aligned}
$$

The basic transformations are calculated using Equation 1 as follows:

$$
\mathrm{T}=\left[\begin{array}{cccc}
\mathrm{s}_{23} \mathrm{c}_{1} \mathrm{c}_{4}-\mathrm{s}_{1} \mathrm{~s}_{4} & -\mathrm{c}_{4} \mathrm{~s}_{1}-\mathrm{s}_{23} \mathrm{c}_{1} \mathrm{~s}_{4} & \mathrm{c}_{23} \mathrm{c}_{1} & \mathrm{c}_{1}\left(\mathrm{a}_{2} \mathrm{c}_{2}+\mathrm{d}_{1} \mathrm{c}_{23}\right) \\
\mathrm{c}_{1} \mathrm{~s}_{4}+\mathrm{s}_{23} \mathrm{c}_{4} \mathrm{~s}_{1} & \mathrm{c}_{1} \mathrm{c}_{4}-\mathrm{s}_{23} \mathrm{~s}_{1} \mathrm{~s}_{4} & \mathrm{c}_{23} \mathrm{~s}_{1} & \mathrm{~s}_{1}\left(\mathrm{a}_{2} \mathrm{c}_{2}+\mathrm{d}_{4} \mathrm{c}_{23}\right) \\
-\mathrm{c}_{23} \mathrm{c}_{4} & \mathrm{c}_{23} \mathrm{~s}_{4} & \mathrm{~s}_{23} & \mathrm{~d}_{1}+\mathrm{a}_{2} \mathrm{~s}_{2}+\mathrm{d}_{4} \mathrm{~s}_{23} \\
0 & 0 & 0 & 1
\end{array}\right]
$$

where $\mathrm{s}_{1}=\sin \theta_{1}, \mathrm{c}_{1}=\cos \theta_{1}, \mathrm{~s}_{23}=\sin \left(\theta_{2}-\theta_{3}\right) \mathrm{c}_{23}=\cos \left(\theta_{2}-\theta_{3}\right)$.

\subsection{Analytical inverse kinematics}

The conversion of the position and orientation of the manipulator's end-effector from Cartesian space to joint space is known as inverse kinematics. The analytical approach is provided in this section for solving the inverse kinematics of a robot arm. To find the second and third joint angles, the inverse closed-form kinematic solutions are obtained as shown in Table 3.1.

Table 3.1. Inverse kinematics solution

\begin{tabular}{|l|l|}
\hline 1. & From the position matrix, get $\mathrm{X}, \mathrm{Y}$, and $\mathrm{Z}$ \\
\hline 2. & From the orientation matrix, get the roll, pitch, and yaw angles \\
& $\begin{array}{l}\text { Roll }=\gamma=\theta_{4} \\
\text { Pitch }=\beta=\theta_{23}=\theta_{2}+\theta_{3} \\
\text { Yaw }=\alpha=\theta_{1}=\operatorname{atan} 2(\mathrm{Y}, \mathrm{X})\end{array}$ \\
\hline 3. & Calculate the second joint angle: $\theta 2=\operatorname{atan} 2\left(\sin \theta_{2}, \cos \theta_{2}\right)$ \\
& where, $\cos \theta_{2}=\frac{\sqrt{\left(\mathrm{P}_{\mathrm{x}}^{2}+\mathrm{P}_{\mathrm{y}}^{2}\right)-\mathrm{d}_{4} \mathrm{c}_{23}}}{\mathrm{a}_{2}}$ and $\sin \theta_{2}=\frac{\left(\mathrm{p}_{\mathrm{z}}-\mathrm{d}_{1}-\mathrm{d}_{4} \mathrm{~s}_{23}\right)}{\mathrm{a}_{2}}$ \\
\hline
\end{tabular}


International Journal of Advances in Scientific Research and Engineering (ijasre), Vol 6 (11), November -2020

4. $\quad$ Calculate the third joint angle: $\theta_{23}=\theta_{2}-\theta_{3}, \theta_{3}=\theta_{23}-\theta_{2}$

\subsection{DC motor position control}

In this block, three main hardware components are implemented for this research. Arduino Mega microcontroller is to control the position of the DC motor by controlling the input voltage to the motor. PID tuning algorithms are implemented in the microcontroller to execute the PWM signal for driving the DC motor. A $12 \mathrm{~V} \mathrm{DC}$ gear-motor is used as an actuator to drive the position control system. The actual shaft position measured by the encoder is fed to the controller as the feedback signal. The description of the dc motor position control system block diagram is shown in Figure 3.2. All four motors are controlled using four PID controllers as inner loop position control.

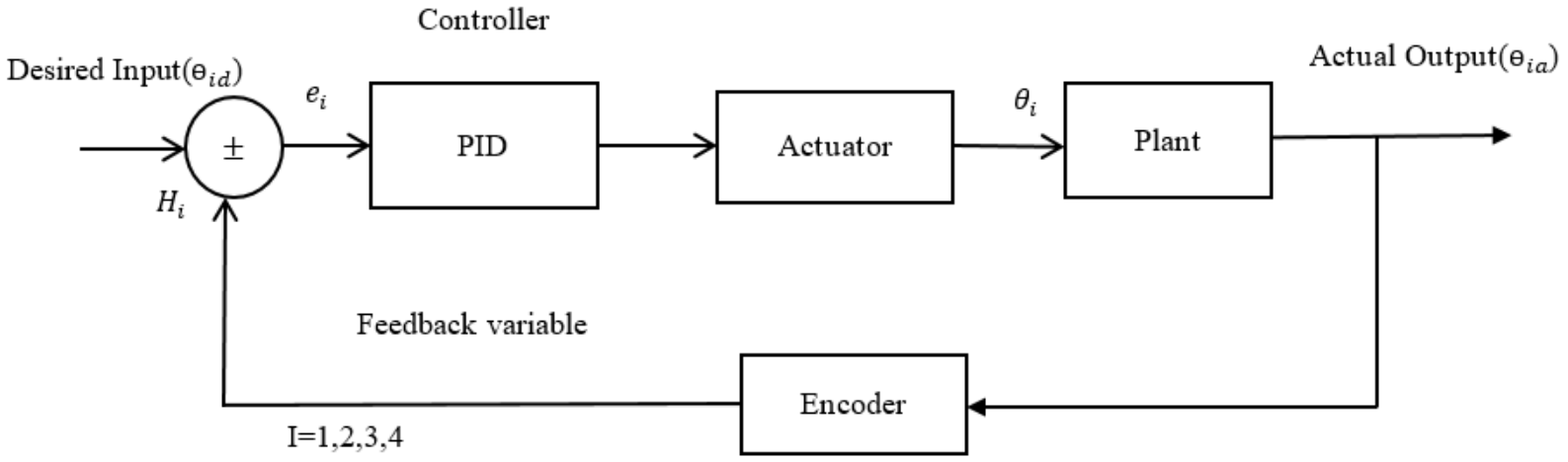

Figure 3.2: dc motor position control system

\section{SYSTEM OVERVIEW OF ROBOT ARM SYSTEM}

This is the system overview of the robot arm system shown in Figure 4.1. The desired position and orientation of the end effector is sent to the controller as the input from the computer. Atmega328 microcontroller is used in this research. A microcontroller is used to generate the pulse to drive the motors of the robot arm. The actual robot arm position is measured by the encoder and it's fed to the controller as the feedback signal.

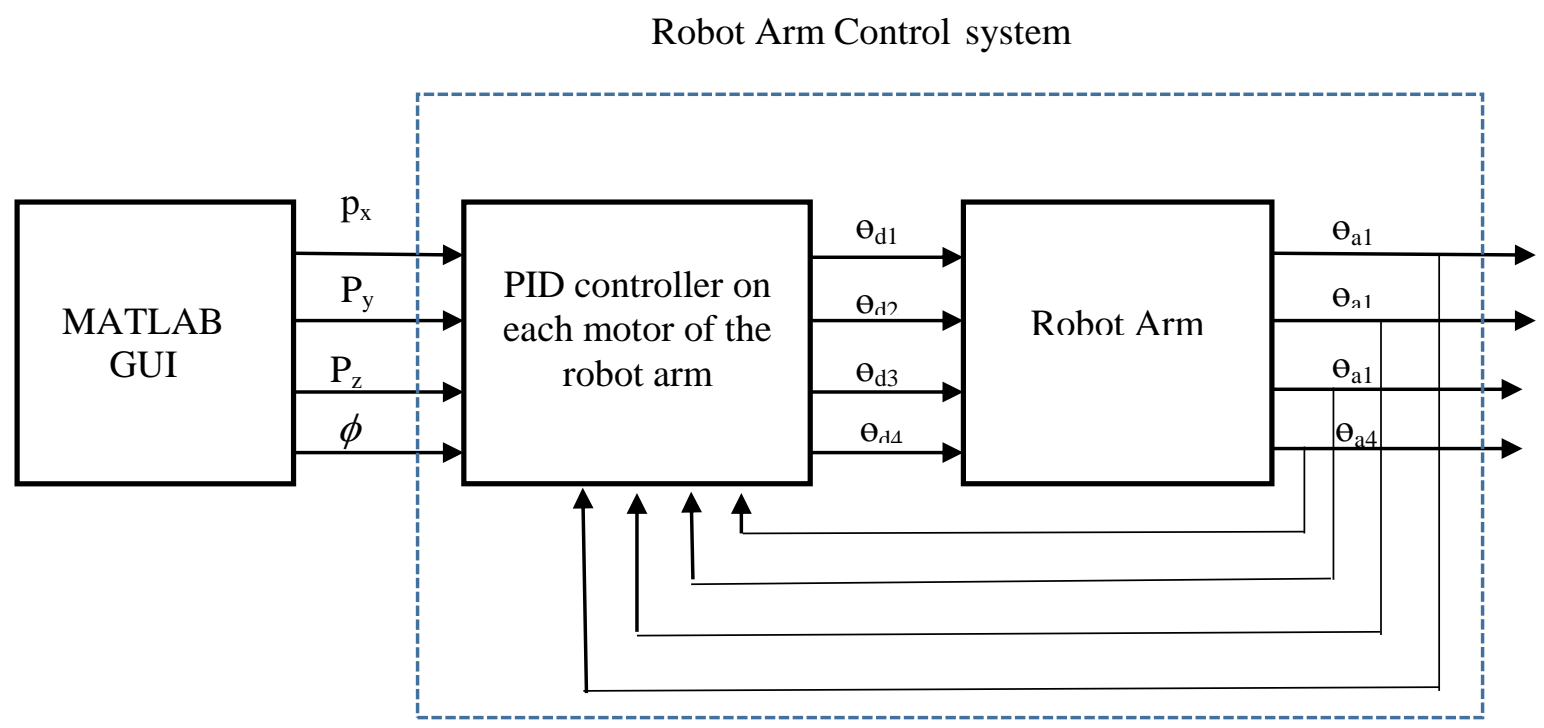

Figure 4.1: System block diagram of research 


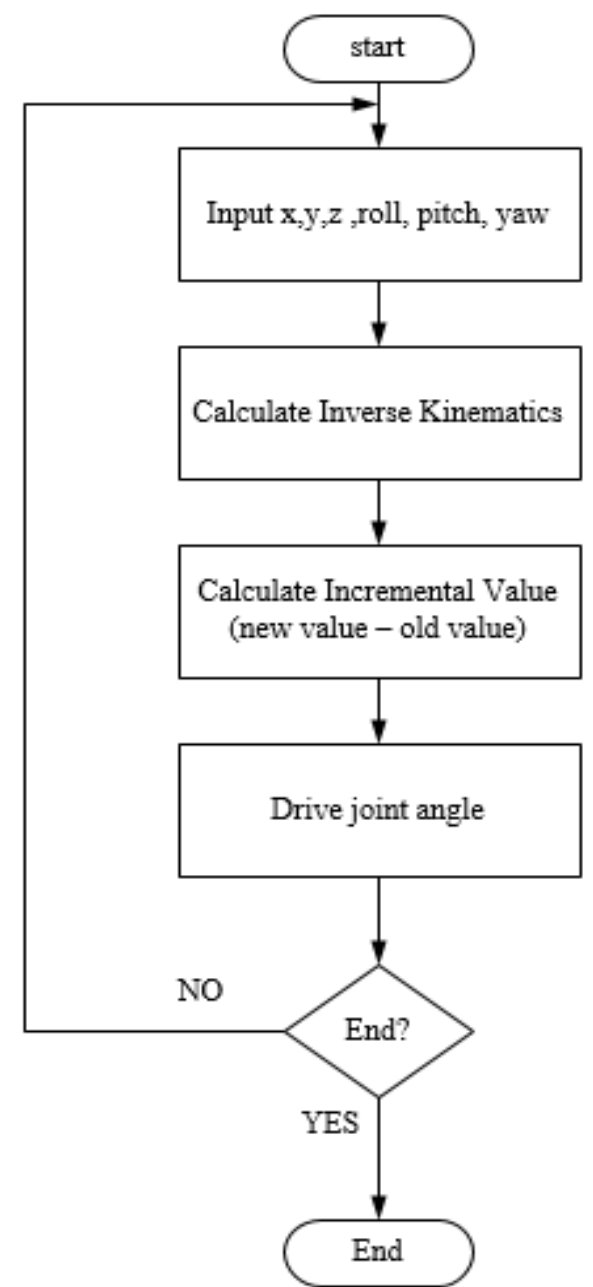

Figure 4.2: General flow chart of pick and place articulated robot arm

The PID control tuning method was implemented to obtain the desired performance of the robot arm motion to achieve zero percentage overshoot and steady-state error, and the shortest possible response time. The PID controller to the robot arm was able to correct the error made by the DC motor and controlling the motor to the desired point. There are four DC motors are used as actuators at each joint of the robot arm. Base, shoulder, and elbow motors have the specifications of the gear ratio is 1:103 and maximum output speed, $60 \mathrm{rpm}$. The wrist motor gear ratio is 1:298 and its maximum output speed is $39 \mathrm{rpm}$.

When XYZ and roll, pitch, yaw coordinates are achieved as the input in MATLAB GUI, inverse kinematic analysis is performed according to the specified coordinate. The resulted data is in an absolute coordinate system. Therefore, the data has to be transformed from absolute value to incremental value to get proper continuous movement and to drive the motor at each joint of the robot arm. And then, the manipulator has to move from its origin to the specified coordinate of the data, incrementally. According to this process, a general flow chart of the 4-DOF articulated robot arm is shown in Figure 4.2.

\section{EXPERIMENTAL RESULTS}

In this section, the experimental result of the pick and place robot arm system is divided as the experimental result of the control system and experimental results of the pick and place process tracking. 
International Journal of Advances in Scientific Research and Engineering (ijasre), Vol 6 (11), November -2020

In this research, four PID controllers are added to the system to have a stable movement of robot arm position. Moreover, the PID gain tuning method is used for the control system to operate well, especially it has a little overshoot, small rise time, no oscillation, and steady-state error is nearly zero to accomplish the designed criteria of the control system.

Table 5.1. Motor Parameters and PID values

\begin{tabular}{|l|c|c|c|c|}
\hline & Base & Shoulder & Elbow & Wrist \\
\hline J & $5.652 \mathrm{e}-06$ & $9.4486 \mathrm{e}-06$ & $3.295 \mathrm{e}-05$ & $2.326 \mathrm{e}-07$ \\
\hline K & 0.015455 & 0.088464 & 0.061314 & 0.0080553 \\
\hline L & 0.00010671 & 0.30964 & 0.02186 & 0.14545 \\
\hline R & 10.571 & 14.465 & 8.2375 & 23.611 \\
\hline b & $3.7843 \mathrm{e}-05$ & $6.0654 \mathrm{e}-06$ & $8.4688 \mathrm{e}-06$ & $1.5387 \mathrm{e}-07$ \\
\hline Gear Ratio & $1 / 103$ & $1 / 103$ & $1 / 103$ & $1 / 298$ \\
\hline P & 92.9359 & 26.01 & 26.01 & 90.0281 \\
\hline I & 6.5546 & 10.24 & 10.24 & 4.002 \\
\hline D & 234.6843 & 0.0014 & 0.0014 & 186.501 \\
\hline Filter Coefficient & 6818.33 & 6509.78 & 6509.78 & 2767.61 \\
\hline
\end{tabular}

For identification of the DC motors, MATLAB \& Simulink parameter estimation toolbox is used after experimental data were achieved individually driving the motors along with their link weights. In the data achieving process, three inputs (sine, Fourier, and square waves) for driving a DC motor are implemented. According to the estimated motor parameters, PID gains are tuned using MATLAB \& Simulink. The estimated DC motor parameters and tuned PID values are illustrated in Table 5.1. Therefore, the experimental results are very optimal to get the desired position of the DC motor using the below PID values.

\subsection{Experimental results of the pick and place process tracking}

The volume of work of the robotic manipulator is limited by the length of its links and the articular limitations of the manipulator. Since the limits of Base and Wrist joint angles are specified as from -120 to +120 degree. The limit of shoulder joint angles is -30 to +120 and the elbow joint has the limitation of -120 to +30 degree. To drive the robot arm, the programming code is implemented using MATLAB GUI on PC for the position representation of the pick and place condition. In Figure 5.1, the MATLAB GUI of the manipulator is presented. In this GUI, the forward and inverse kinematics can be easily checked whether they contribute an exact solution or not. And the control command is sent to the robot's Arduino controller using serial communication. 
International Journal of Advances in Scientific Research and Engineering (ijasre), Vol 6 (11), November -2020

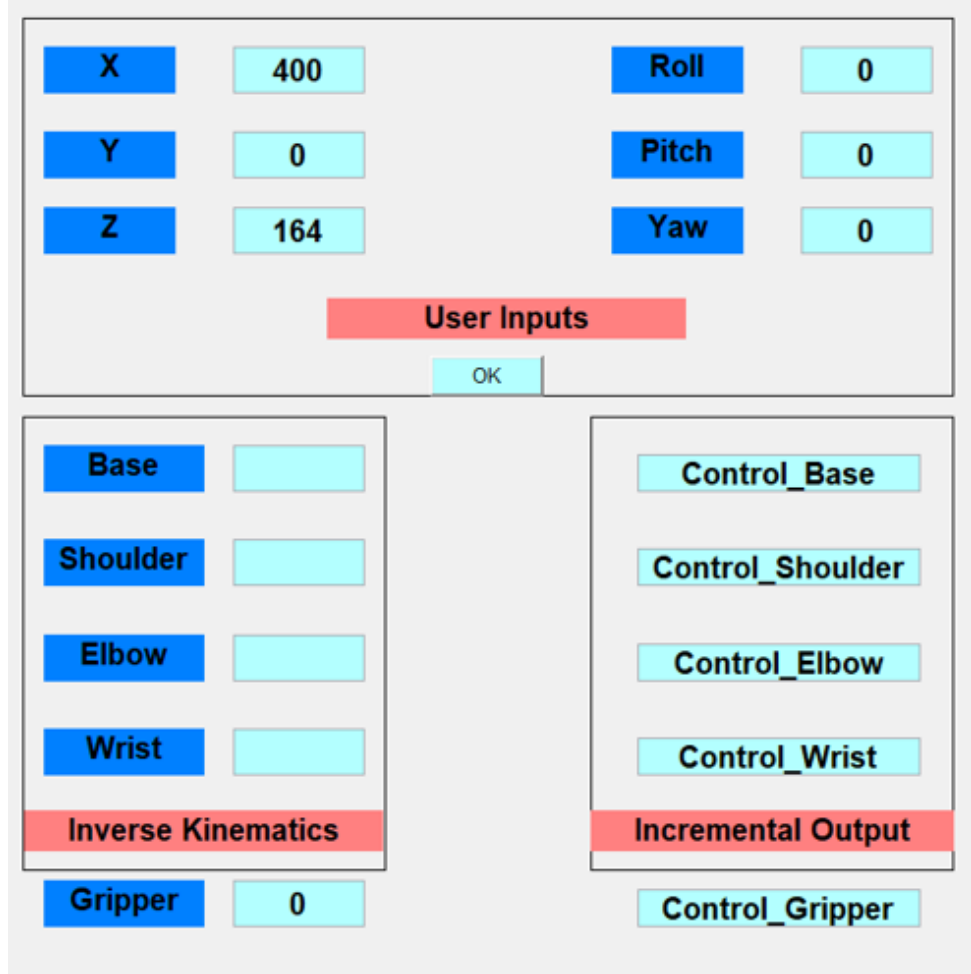

Figure 5.1: Robot Drive GUI

According to the structure of the robot arm, the home position of the robot arm is assumed at $x=400 \mathrm{~mm}, y=0 \mathrm{~mm}$, and $\mathrm{z}=164 \mathrm{~mm}$. Testing the home position of the robot arm (all dc motors angles are $0 \circ$ applied) is shown in Figure 5.2 .

After home position, let position 1 to be at $\mathrm{x}=364 \mathrm{~mm}, \mathrm{y}=0 \mathrm{~mm}$, and $\mathrm{z}=-1 \mathrm{~mm}$ respectively. The original object position is set at position 1 and the final object position is set at position 3. The inverse kinematic method is used to reach the robot arm at position 1. The distance of position 1 is applied to the inverse kinematic equation, the angles of dc motors $\left(\theta 1=0^{\circ}, \theta 2=-30^{\circ}, \theta 3=\right.$ $-8 \circ, \theta 4=0 \circ$, ) are obtained. Other positions are also calculated as the above description. The result angles are applied to dc motors that are connected to robot arm joints.

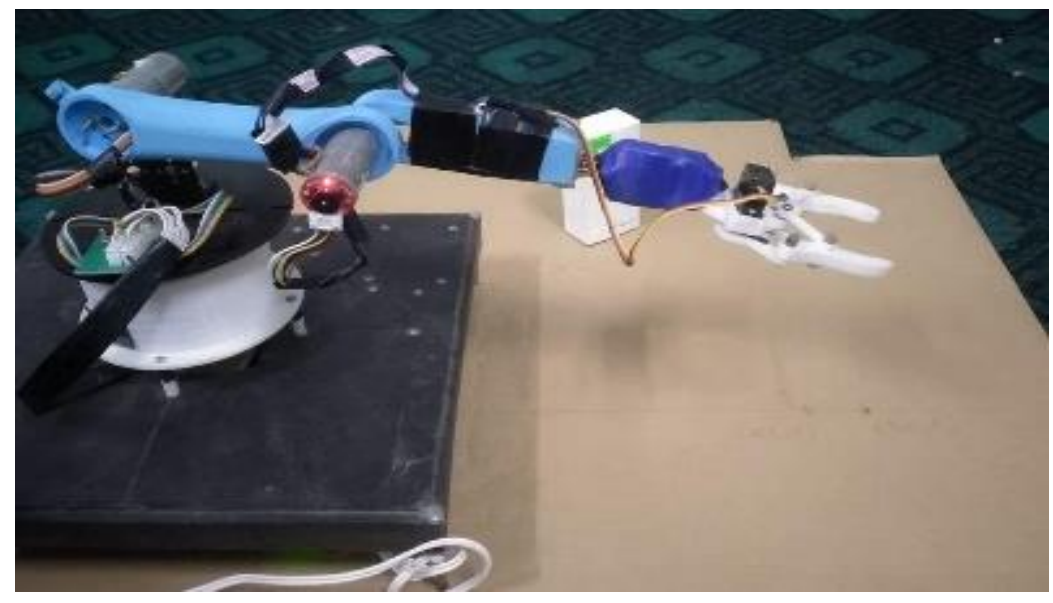

Figure 5.2: Robot arm at the home position (all angles, $0^{\circ}$ ) 


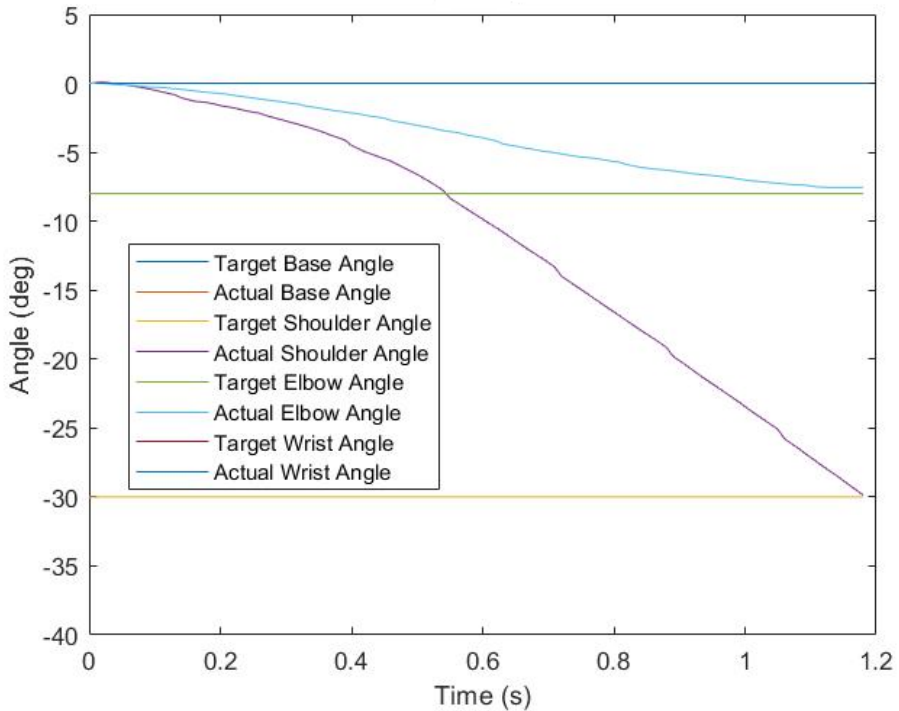

(a) Position 1

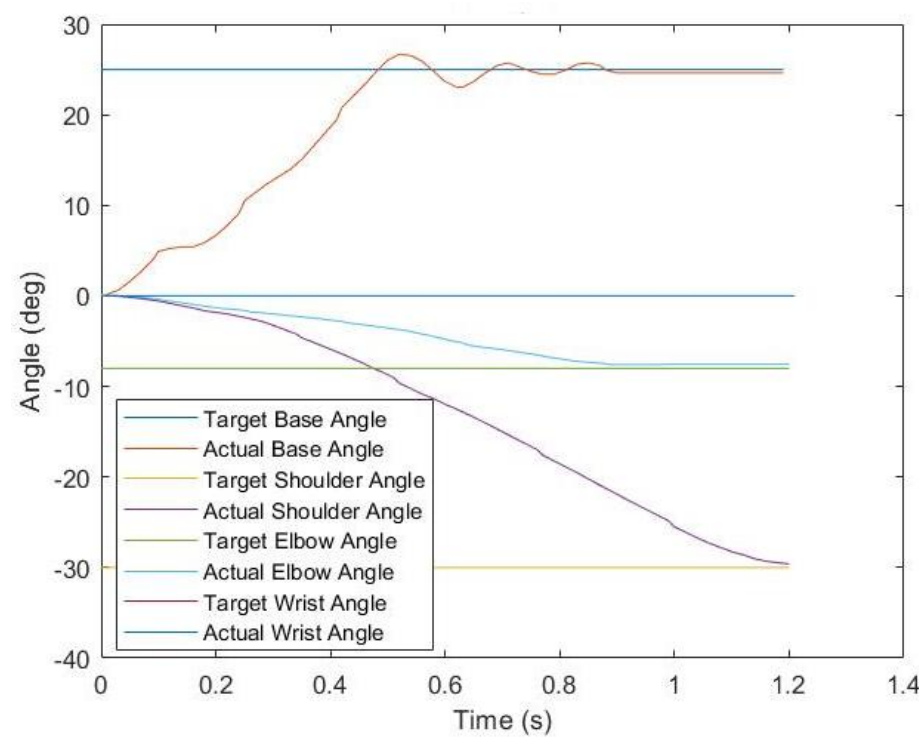

(c) Position 3

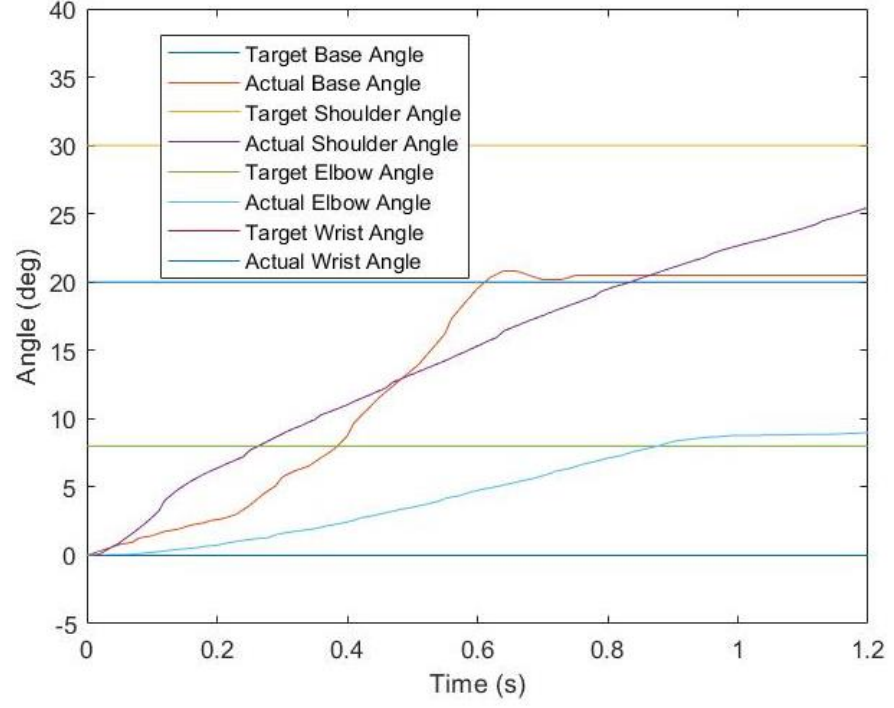

(b) Position 2

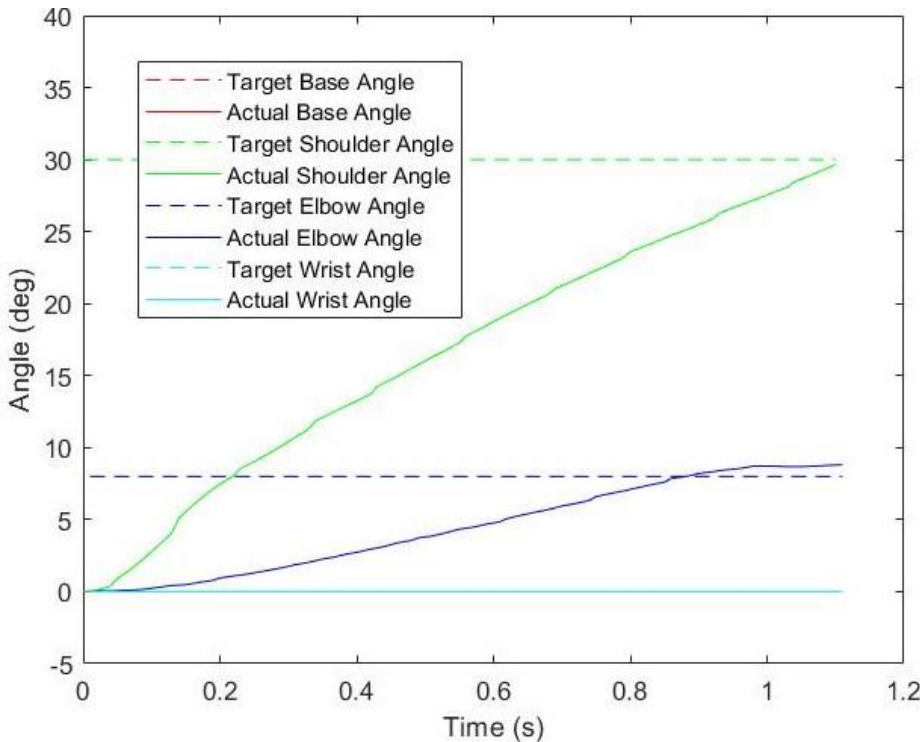

(d) Position 4

Figure 5.3: Experimental result of reaching positions

Figure 5.3 shows the simulation results of moving the robot arm joints from the home position to position 1, position 2 , position 3, and position 4, respectively. Robot arm pickup condition has the position value of $\mathrm{x}=376 \mathrm{~mm}, \mathrm{y}=137 \mathrm{~mm}, \mathrm{z}=164$ $\mathrm{mm}$, roll $=0$, pitch $=0$ and yaw $=20$ respectively in Figure 5.3 (a). After that the pickup condition, the manipulator use this value $\mathrm{x}=257 \mathrm{~mm}, \mathrm{y}=257 \mathrm{~mm}, \mathrm{z}=-1 \mathrm{~mm}$, roll $=0$, pitch $=-22$, yaw $=45$ to reach at the place condition of position 3 and its result is as illustrated in Figure 5.3 (b). After that the position 3, the robot arm released the object and it ended the object place process. And then, the robot arm has been moved a little to the side to reach position 4 ( $\mathrm{x}=283 \mathrm{~mm}, \mathrm{y}=283 \mathrm{~mm}, \mathrm{z}=164 \mathrm{~mm}, \mathrm{roll}=0$, pitch= 0 , yaw $=45$ ) as shown in Figure 5.3 (c) and it returns to the home position as illustrated in Figure $5.3(\mathrm{~d})$.

After testing the robot arm, there is little error occurred between $\pm 0.5 \%$. The position of $\mathrm{X}, \mathrm{Y}$, and $\mathrm{Z}$ coordinate is almost equally similar to the calculated result from the inverse kinematic method. After applying the desired position of the robot arm, there is a little error difference between the desired angles, and the actual angles are presented in Table 5.1.

Table 5.2. Error calculation of experimental testing 
International Journal of Advances in Scientific Research and Engineering (ijasre), Vol 6 (11), November -2020

\begin{tabular}{|c|c|c|c|c|}
\hline Point & Joint & Target Angle (Degree) & Actual Angle (Degree) & Error (Degree) \\
\hline \multirow{4}{*}{ Home to P1 } & Base & 0 & 0 & 0 \\
\hline & Shoulder & -30 & -30 & 0 \\
\hline & Elbow & -8 & -7.8 & 0.2 \\
\hline & Wrist & 0 & 0 & 0 \\
\hline \multirow{4}{*}{ P1 to P2 } & Base & 20 & 19.8 & 0.2 \\
\hline & Shoulder & 30 & 30 & 0 \\
\hline & Elbow & 8 & 29.6 & 0.4 \\
\hline & Wrist & 0 & 0 & 0 \\
\hline \multirow{4}{*}{$P 2$ to $P 3$} & Base & 25 & 24.9 & 0.1 \\
\hline & Shoulder & -30 & -30 & 0 \\
\hline & Elbow & -8 & -8 & 0 \\
\hline & Wrist & 0 & 0 & 0 \\
\hline \multirow{4}{*}{ P3 to P4 } & Base & 0 & 0 & 0 \\
\hline & Shoulder & 30 & 30 & 0 \\
\hline & Elbow & 8 & 7.7 & 0.3 \\
\hline & Wrist & 0 & 0 & 0 \\
\hline
\end{tabular}

\section{DISCUSSION}

This paper has been researched the 4-DOF articulated robot arm for the pick and place process. In this paper, forward and Inverse kinematic methods have been fully explained and calculated by using D-H parameters and analytical method. From the result of this, an articulated robot arm has been tested for picking and placing the object experimentally. When testing the robot arm for pick up and place process, there is little error occurs. The occurrence of this error is because of the limitation of selected dc motors and some mechanism structure of the robot arm.

\section{CONCLUSION}

The development of a 4-DOF robot arm for simple pick-and-place operations has been considered in this paper. The mathematical model is prepared and solved for angles of joints. The experimental results show that the actual robot position achieved from experiments and calculated inputs are absolutely the same. The robot arm hardware, software, and mathematical calculation parts have been highlighted and tested practically. As the future of advanced robot arm, it can be designed to get an optimum grip on the desired object, it is recommended that a pressure sensor be incorporated on one of the end-effector's fingers. Moreover, to know the locations of the object (instead of the pre-programmed positions operated in this research), a camera and a computer with image processing capability can be used.

\section{ACKNOWLEDGMENTS}

The author is very thankful to Dr. Aung Win, Rector, University of Technology (Yadanarpon Cyber City), for his encouragement, invaluable permission, and his kind support in carrying out this research work. The author would like to express his deep gratitude to Dr. Htin Kyaw Oo, Professor, Head of Faculty of Electronic Engineering, for his effective guidance, constructive comments, and criticism. The author also wishes to Dr. Lu Maw, Professor, Faculty of Electronic Engineering, for supervision, accomplished guidance, his willingness to share his idea and, helpful suggestions and for his patience, continuous 
International Journal of Advances in Scientific Research and Engineering (ijasre), Vol 6 (11), November -2020

supervision, and encouragement during the period of this research. Finally, a special note of thank is also intended to all who supported her with necessary help for this paper.

\section{REFERENCES}

[1] Surender Kumar, Mukherjee S. K., Robotic Engineering, Smt. Sumitra Handa, First Edition, 2001.

[2] Harish K 1, Megha D 2, Shuklambari M 3, Amit K 4, Chaitanya K Jambotkar 5, Pick and Place Robotic Arm Using Arduino, International Paper of Science, Engineering and Technology Research (IJSETR), December 2017, Volume 6, Issue 12.

[3] War War Naing, Kyi Zar Aung, Aung Thike, Position Control of 3-DOF Articulated Robot Arm using PID Controller, International Paper of Science and Engineering Applications, 2018, Volume 7-Issue 09,254-259.

[4] Mr. C. Chandra Mouli1, Ms. P. Jyothi1, Prof. K. Nagabhushan Raju2, Prof. C. Nagaraja2, Design and Implementation of Robot Arms Control Using LabVIEW and ARM Controller, IOSR Paper of Electrical and Electronics Engineering (IOSRJEEE), (Jul - Aug) 2013, Volume 6, Issue 5.

[5] Myat Noe Wai, Lu Maw, Thwe Thwe Win, Kinematics Modeling and Simulation of the 4-DOF Robotic Manipulator, $1^{\text {st }}$ University Research Conference on Science \& Engineering, 23 ${ }^{\text {rd }}$ Janauary,2020,Vol.1, 50- 54.

[6] Sanjay L., Shweta P, Position Control of Pick and Place Robotic Armll, International Conference on Engineering Innovation and Technology, Nagpur, 1st July 2012.

[7] Jolly Shah, S.S. Rattan, B.C.Nakra, End-Effector Position Analysis Using Forward Kinematics for 5DOF Pravak Robot Arm, International Paper of Robotics and Automation (IJRA), September 2013, Vol. 2, No. 3.

[8] Binbin L., Yimin S., Gang D., Tao S., Yang Q, Dimensional Synthesis of a Planar Parallel Manipulator for Pick-and-Place Operations Based on Rigid-Body Dynamicsll, Intelligent Robotics and Applications/Lecture Notes in Computer Science, Springer, 2012, Vol. 7506, pp. 261-270.

[9] Ahmed Zakari Alassar, Modeling and Control of 5DOF Robot Arm Using Supervisory Control, Degree of Master of Science in Electrical Engineering, The Islamic University of Gaza, Electrical Engineering Department, March 2010.

[10] Ayokunle A. Awelewa, Kenechukwu C. Mbanisi, Samuel O. Majekodunmi, Ishioma A. Odigwe, Ayoade F. Agbetuyi, Isaac A. Samuel, Development of a Prototype Robot Manipulator for Industrial Pick-and-Place Operations, International Paper of Mechanical \& Mechatronics Engineering, November 2013, IJMME-IJENS Vol:13 No:05. 